\title{
The Academic Experiences Survey (AES): Measuring Perceptions of Academic Climate in Liberal Arts Institutions
}

\author{
Kathleen M. Galotti, ${ }^{1}$ Lacey R. Clare, ${ }^{2}$ Courtney McManus, ${ }^{3}$ Andrea Lisa Nixon ${ }^{4}$
}

\begin{abstract}
In today's educational climate, liberal arts institutions must demonstrate that their educational goals are being met. This paper presents reliability and stability testing of a concise, research-based survey instrument designed to examine student perceptions of academic experiences that is particularly suited to institutions rooted in the liberal arts. The Academic Experiences Survey (AES) consists of five scales: Comfortable in College, Skills, Interdisciplinary Understanding, Liberal Arts Integration, and Future Academic Plans. We present data from administrations at two institutions; examining the instrument's validity as prediction of college retention and graduation, enrollment in STEM courses, and longitudinal changes over the course of students' first year in college
\end{abstract}

Keywords: assessment; college students; epistemological development; liberal arts college environments

Colleges and universities are currently finding themselves accountable- to the federal government, to students, parents, accrediting bodies, trustees, and donors - to document that their offerings lead to real and lasting educational change (e.g., U.S. Department of Education, 2006). The growing focus on acquisition of specific, job ready skills and training in higher education has called into question the value of a liberal arts education. In the face of that, institutions are being held accountable. This call for reliable and valid assessment measures pressures and provides incentives for institutions of higher education to demonstrate that their goals are in fact being met or at least addressed (Bloxham \& Boyd, 2007; Heywood, 2000; Palomba \& Banta, 1999; Suskie, 2009; Secolsky \& Denison, 2012).

As institutions develop relevant assessment tools, they need to understand not only what skills and knowledge bases students gain, but also how students develop more broadly, e.g., in their perception of what knowledge is and what the goals of education are. Liberal arts institutions, we argue, hold goals including creating a comfortable environment where students can question; fostering interdisciplinary understanding, fostering liberal arts understanding, and developing strong academic skills. Assessing relevant outcomes for such goals may not be possible with existing institutional assessment instruments.

Studies of cognitive development in college students suggest that there is a gradual increase in skills or proclivities such as reflective judgment (Kitchener \& King, 1981; King \& Kitchener,

\footnotetext{
${ }^{1}$ Carleton College, 1 N College Street, Northfield, MN 55057 email kgalotti@carleton.edu

${ }^{2}$ Carleton College, $1 \mathrm{~N}$ College Street, Northfield MN 55057

${ }^{3}$ Colby-Sawyer College, 541 Main St. New London, NH 03257 email courtney.mcmanus@colby-sawyer.edu

${ }^{4}$ Carleton College, 1 N College Street, Northfield MN 55057
} 
1994, 2004) or epistemological development (Clinchy, 2002; Hofer, 2001; Perry, 1970) as well as a decrease in dependence on external authorities (Magolda, King, Talyor, \& Wakefield, 2012) over students four undergraduate years, and especially over their first year (Seifert, Goodman, King, Magolda, 2010).

Our work examines one aspect of this development, specifically, the understanding of the purposes and goals of a liberal arts education. It has been assumed that students understand that a liberal arts education fosters lifelong learning and the development and refinement of critical thinking skills, broader objectives than career preparation skills or technical training (Nussbaum, 2010). But we know surprisingly little about what incoming college students think about the purpose of such an education. We describe the development and testing of a new instrument, the Academic Experiences Survey (AES), designed to measure students' perceptions of several dimensions of a liberal arts experience and demonstrate its utility in examining the critical issue of retention at the institutional level and specifically in STEM courses.

Current assessment measures in higher education largely focus either on specific disciplinary knowledge (e.g., GRE exams in specific subject areas); the measurement of more general skills, such as analytical reasoning, critical thinking, problem solving, or written communication competency (see for example, the Collegiate Learning Assessment or CLA+; Klein, Benjamin, Shavelson \& Bolus, 2007) self-reported behaviors, such as the frequency with which students work with professors, read books beyond those assigned in a class, or ask questions in class (for example, the National Survey of Student Engagement [NSSE]; Kuh, 2001), or general aspects of campus climate, focusing on students' feeling of belongingness and participation (Hurtado, Griffin, Arellano \& Cuellar, 2008).

Our instrument focuses less on specific knowledge, skills or behaviors, and more on students' overall attitudes toward learning in a liberal arts context. This work began in 1998, when the first author collaborated with colleagues from two other departments to create a "Triad" of courses in which the same cohort of 48 incoming first-year students enrolled, comprising most of their course load for the first trimester. The faculty members involved investigated whether Triad students showed any differences when compared with non-Triad students (enrolled in another section of the same biology course in their first trimester at the same institution), in their attitudes toward their college experience. We asked questions of students at the end of their first trimester, including: What skills did they feel they had acquired? How much were they able to draw connections across disciplines? How much intellectual challenge had they felt? How comfortable were they with ambiguity? Findings showed that Triad students reported themselves significantly more able to grasp theoretical issues, and to have a better understanding of the purpose of a liberal arts education (Elveton, Galotti, Komatsu, Rand \& Singer, 2000)).

That study centered on students' attitudinal responses to their first trimester at college. It did not look at whether and how those attitudes changed over time or related to specific coursework or to other existing measures of cognitive functioning. It did not examine whether or not responses predicted academic decision-making characteristics. The AES is an expansion of the original survey given in 1998. It consists of 45 items grouped into five scales: Comfortable in College (feeling at ease, engaged, and comfortable at one's educational institution); Skills (feeling mastery of writing, critical thinking, reading, and other academic skills); Future (Academic) Plans (making course, major, sophomore housing, and first-year summer choices with an eye toward future goals); Interdisciplinary Understanding (seeing connections among and across different disciplines); and Liberal Arts Understanding (understanding what and how different disciplines contribute to a liberal education). Individual items of the AES are presented in Appendix 1.

Journal of the Scholarship of Teaching and Learning, Vol. 16, No. 5, October 2016. josotl.indiana.edu 
The development of the AES was embedded in longitudinal studies examining the academic experiences and decision-making processes of first year students. This afforded us the ability to examine the correlates of AES scale scores, as well as to explore their predictive powers.

Given the prominence of the NSSE (Kuh, 2001) as an institutional-level assessment tool further comparison between it and the AES is warranted. Recent revisions of the core survey and topical modules for the current NSSE provide only very modest overlap with the AES. For example, the Development of Transferable Skills (Center for Postsecondary Research, 2016) module asks about the frequency with which students have written something that "included ideas from more than one academic discipline.” In contrast, the AES “Interdisciplinary Understanding” scale, described below, prompts student responses to nine elements and lends itself to a more full examination of student perceptions of interdisciplinarity. For institutions already using the NSSE, the AES could provide an important complement to the NSSE to more fully examine epistemological development. For institutions committed to assessment instruments other than the NSSE, the AES may provide an even more critical complement to their existing survey instruments.

\section{Method}

\section{Participants}

Participants were first-year students from both Carleton College and Colby-Sawyer College The first cohort from Carleton College, who were recruited in the fall of 2009, consisted of 101 firstyear students (39 male) who responded to a letter of invitation sent to all 520 first-year students. Of these 101 students, 94 (35 male) returned for a second session in the winter of 2010; 93 (34 male) returned for a third session in the spring of 2010, and 88 (33 male) returned for a fourth session in the fall of 2010. Although specific racial/ethnicity data were not collected on the sample, the overall population of first-year Carleton College students in the fall of 2009 included 22\% who self-reported their racial group as African American, Asian American, Hispanic/Latino/Chicano, or Native American (Lawrence, 2010a ).

The second cohort of participants from Carleton College, who were recruited in the fall of 2010, consisted of 48 first-year students (12 male). Of these, 45 (12 male) returned for a second and third session in the winter and spring of 2011 (respectively), and 44 (12 male) returned for a fourth session in the fall of 2011. Students were recruited through a letter of invitation that was sent to 200 quasi-randomly selected first-year students ${ }^{5}$. The composition of the first-year class of students entering in 2010 was also 22\% students of color, not including international students (Lawrence, 2010b)

Participants from both cohorts were paid $\$ 10.00$ for the first two sessions, $\$ 12.50$ for the third session, and $\$ 25.00$ for the fourth session.

The third and fourth cohorts of participants from Colby-Sawyer College were recruited in the fall of 2011 and fall of 2012 (respectively). The third cohort consisted of 375 first-year students (98 male) of the entire class of 476. The fourth cohort consisted of 386 first-year students (85 male) of the entire class of 437. Students were recruited from a required first year experience

\footnotetext{
5 Students who opted to remove their names from the college's public directory were not sent invitations. Moreover, international students were excluded from invitations, as their visa status made compensation an issue. Of the remaining students, invitations were sent randomly. Journal of the Scholarship of Teaching and Learning, Vol. 16, No. 5, October 2016. josotl.indiana.edu 
course for all incoming students. Students younger than 18 years of age (the legal age to sign an informed consent document) were excluded, as were any students who declined to participate (less than 1\%) or were absent the day data were collected. The overall population of all Colby-Sawyer College students included approximately nine percent international students and $12 \%$ who identified themselves as ethnic minority students (Colby-Sawyer 2013).

\section{Materials and Procedure}

At Carleton College, trained undergraduate research assistants ran sessions in small groups. A number of different instruments were administered during the different sessions. ${ }^{6}$ At ColbySawyer College, sessions were run in class where each student received a packet with several surveys ${ }^{7}$ counterbalanced for order. Each student was given as much time as needed to complete the questionnaires, typically in the range of 20 to 25 minutes. A brief description of the instruments used in this paper follows.

Academic Experiences Survey (AES). This instrument, developed for this study, consists of 45 items, divided equally into five scales. These scales, with example items, include the following: Comfortable at College ("I feel comfortable/at ease most of the time when I am at [College 1]”), Skills ("I have strong critical thinking skills”), Interdisciplinary Understanding ("I understand the connections among different disciplines, such as the humanities, sciences, and social sciences"), Liberal Arts Understanding ("My classes this term offer me a reasonable and broad view of intellectual inquiry”), and Future (Academic) Plans ("In the future I plan to take classes that build on what I'm learning in my current classes"). This measure was used at both Carleton College (during sessions two through four) and Colby-Sawyer College (during a single session).

Need for Cognition (NFC). This instrument, developed by Cacioppo and Petty (1982), consists of 34 statements that measure a person's tendency to engage in and enjoy effortful cognitive activity, such as reasoning or problem solving. Example items include "I really enjoy a task that involves coming up with new solutions to problems", or "I prefer my life to be filled with puzzles that I must solve”. This measure was used at both Carleton College (in two sessions-the first and fourth) and Colby-Sawyer College (once).

Planning Survey (PS). The planning survey (Simons \& Galotti, 1992) presents statements about the subject's self-reported use of planning strategies and organization of information. Example statements include "I write down appointments and meetings on a calendar", and "I have a written list of goals for each day". This measure was used at both Carleton College (in two sessions - the first and fourth) and Colby-Sawyer College (once).

Factors and Options Worksheet (FAOW). This instrument, adapted from previous research, ( Galotti, 1999, 2007; Galotti \& Tinkelenberg, 2009) was used to provide a systematic way for participants to describe the options under active consideration, as well as the criteria they reported using to evaluate those options for different upcoming decisions. These decisions were: choosing courses for the following term (participants did an FAOW for this decision in the first three sessions), choosing a major (done twice, once in the second session and once in the fourth),

\footnotetext{
${ }^{6}$ For a complete listing of all instruments administered at Carleton College please email the first author.

${ }^{7}$ For a complete list of instruments used at Colby-Sawyer College, contact the third author. Journal of the Scholarship of Teaching and Learning, Vol. 16, No. 5, October 2016. josotl.indiana.edu 
choosing housing for the following year, choosing plans for the summer (these last two decisions were surveyed both during the third session).

The worksheet consisted of a grid containing ten columns of blanks. In the second column participants were asked to list the criteria by which they were currently evaluating their options. Each criterion was rated for its importance on a ten-point scale (" 1 " = "Not very important", " 10 " = "Extremely important"), and these weights were placed in the first column. At the top of the third through tenth column, the options under active consideration were listed. Participants rated the options based on how well they fulfilled each of these criteria using a ten-point scale. Table 1 provides a fictitious example of a version of this instrument for the decision, choosing a major. This measure was used only at Carleton College.

Table 1. Fictitious Example of a Completed FAOW Sheet for Choosing a College Major

\begin{tabular}{|l|l|l|l|l|}
\hline Factor & $\begin{array}{l}\text { Importance } \\
\text { Weight }\end{array}$ & $\begin{array}{l}\text { Option 1 } \\
\text { Psychology }\end{array}$ & $\begin{array}{l}\text { Option 2 } \\
\text { Biology }\end{array}$ & $\begin{array}{l}\text { Option 3 } \\
\text { English }\end{array}$ \\
\hline Average Class Size & 3 & 8 & 2 & 6 \\
\hline Professor Quality & 7 & 9 & 7 & 8 \\
\hline $\begin{array}{l}\text { Major } \\
\text { Requirements }\end{array}$ & 9 & 10 & 2 & 5 \\
\hline $\begin{array}{l}\text { Career } \\
\text { Opportunities }\end{array}$ & 8 & 6 & 10 & 2 \\
\hline $\begin{array}{l}\text { Laboratory } \\
\text { Requirements }\end{array}$ & 5 & 7 & 3 & 10 \\
\hline
\end{tabular}

Journal of the Scholarship of Teaching and Learning, Vol. 16, No. 5, October 2016. josotl.indiana.edu 


\section{Results}

\section{Internal Reliabilities of AES Scales}

We first ran internal reliability analyses on the five AES scales and the overall total AES score from the two Carleton College cohorts combined (total number of included participants was 137 or 138, depending on the specific scale, due to missing responses). Internal reliabilities, computed with Cronbach's alpha were as follows: Comfortable in College, .71; Skills, .84; Liberal Arts Understanding, .81; Interdisciplinary Understanding, .81; Future Plans, .59; and Overall, .91. For the Colby-Sawyer sample (approximate $N=717-744$, depending on the specific scale, due to missing responses), the corresponding values were .72, .84, .81, .84, .62, and .93. Thus, internal reliability was acceptable to good for all of the scales with the possible exception of Future Plans.

We looked for gender differences on scale scores, again separately by institution. Carleton College students showed no significant gender differences on any of the AES scales nor on the overall AES scale. For Colby-Sawyer students, there was a significant difference on both the Liberal Arts Understanding scale, with males $(M=43.27, S D=11.51)$ scoring significantly lower than females $(M=46.58, S D=8.40), t$ [246.27] $=3.60, \boldsymbol{p}<.001$, and the Interdisciplinary Understanding scale, with males $(M=43.40, S D=11.23)$ scoring significantly lower than females $(M=45.66, S D=8.45), t[250.45]=2.51, \boldsymbol{p}<.05$.

\section{Longitudinal Stability of AES Scale Scores}

We next looked to see how stable the AES scale scores were over time, using just the Carleton College sample, who responded to the scale on three occasions (sessions 2-4). Table 2 presents correlations among AES scores over different intervals of time. Unsurprisingly, correlations are strongest over adjacent intervals. Scores for all scales except Future Planning are moderately strong, even across long intervals.

Table 2. Longitudinal Correlations for AES Scores

\begin{tabular}{|l|l|l|l|}
\hline AES Score & $\begin{array}{l}\text { Session 2-3 } \\
\text { (First Year) }\end{array}$ & $\begin{array}{l}\text { Session 3-4 } \\
\text { (First-Second } \\
\text { Year) }\end{array}$ & $\begin{array}{l}\text { Session 2-4 } \\
\text { (First-Second } \\
\text { Year) }\end{array}$ \\
\hline Comfortable & $.82^{* * *}$ & $.24 * *$ & $.40^{* * *}$ \\
\hline Skills & $.78^{* * *}$ & $.79 * * *$ & $.46^{* * *}$ \\
\hline Liberal Arts & $.77^{* * *}$ & $.52 * * *$ & $.50^{* * *}$ \\
\hline Interdisciplinary & $.76^{* * *}$ & $.64 * * *$ & $.27 * *$ \\
\hline & & \multicolumn{2}{|l}{} \\
\hline
\end{tabular}

Journal of the Scholarship of Teaching and Learning, Vol. 16, No. 5, October 2016. josotl.indiana.edu 


\begin{tabular}{|l|l|l|l|}
\hline Future Planning & $.76^{* * *}$ & $.28^{* * *}$ & $.24^{* *}$ \\
\hline $\begin{array}{l}\text { Overall AES } \\
\text { Score }\end{array}$ & $.94^{* * *}$ & $.64^{* *}$ & $.48^{* * *}$ \\
\hline
\end{tabular}

${ }^{*} \mathrm{p}<0.05, \quad{ }^{* *} \mathrm{p}<0.01, \quad * * * \mathrm{p}<0.001$

We also analyzed the changes in scale scores for the 131 students who participated in the second, third, and fourth sessions. Table 3 presents these means. A repeated measures ANOVA revealed a main effect for scale $(\mathbf{F}[4,520]=20.79, \mathbf{p}<.001$, partial eta squared $=.14$, MS error $=34.63)$, session $(\mathbf{F}[2,260]=7.39, \mathbf{p}<.001$, partial eta squared $=.05$, MS error $=34.69)$, and the interaction between scale and session $(\mathbf{F}[8,1040]=13.95, \mathbf{p}<.001$, partial eta squared $=.10$, MS error $=22.12$ ). Post-hoc Tukey tests indicated different patterns of change for different scales, as shown in Table 3.

Table 3. Mean AES Scale Scores Over Time ${ }^{1}$

\begin{tabular}{|l|l|l|l|}
\hline AES Scale Score & Session 2 & Session 3 & Session 4 \\
\hline Comfortable & 53.98 & 53.74 & 52.21 \\
\hline Skills & $51.63_{\mathrm{a}}$ & 50.13 & $48.12_{\mathrm{b}}$ \\
\hline Liberal Arts & $51.56_{\mathrm{a}}$ & $55.43_{\mathrm{b}}$ & $51.79_{\mathrm{a}}$ \\
\hline Interdisciplinary & $52.57_{\mathrm{a}}$ & 50.72 & $50.41_{\mathrm{b}}$ \\
\hline Future Planning & $51.42_{\mathrm{a}}$ & $51.67_{\mathrm{a}}$ & $53.40_{\mathrm{b}}$ \\
\hline $\begin{array}{l}\text { Overall AES } \\
\text { Score }\end{array}$ & $261.17_{\mathrm{a}}$ & $261.69_{\mathrm{a}}$ & $256.03_{\mathrm{b}}$ \\
\hline
\end{tabular}

${ }^{1}$ Within each row, means with different subscripts differ significantly $(\mathbf{p}<.01)$.

A separate repeated measures ANOVA on total AES scores showed a main effect for session $(\mathbf{F}[2,260]=7.39, \mathbf{p}<.001$, partial eta squared $=.05$, MS error $=173.43)$. Post-hoc Tukey tests revealed that the Overall mean in the sophomore year was significantly lower than the Overall mean in either of the two sessions conducted during the first year. Journal of the Scholarship of Teaching and Learning, Vol. 16, No. 5, October 2016. josotl.indiana.edu 


\section{Correlation of AES Scores with GPA, Retention, and Graduation Rates}

The Colby-Sawyer sample included a little less than $80 \%$ of their fall 2011 entering class, for whom we also had data on grade point averages, retention, and graduation. We found none of the five scale scores correlating significantly with first-year GPA. The Skills score and the Overall score correlated with high school GPA ( $\mathbf{r}=.13, \mathbf{p}<.05$, and $\mathbf{r}=.12, \mathbf{p}<.05$, respectively) but no other AES score showed statistically significantly correlations. The Comfortable in College score correlated with fall-to-spring retention during the first year $(\mathbf{r}=.14, \mathbf{p}<.01)$ as well as with springfall (sophomore year) retention $(\mathbf{r}=.13, \mathbf{p}<.05)$. The Overall AES score also correlated significantly with spring-fall (sophomore year) retention $(\mathbf{r}=.11, \mathbf{p}<.05)$. No other AES scores correlated significantly with retention measures. The Interdisciplinary Understanding scale $(\mathbf{r}=$ $.11, \mathbf{p}<.05)$, the Comfortable in College scale $(\mathbf{r}=.12, \mathbf{p}<.05)$, and Future Planning scale $(\mathbf{r}=$ $.12, \mathbf{p}<.05)$ correlated significantly with 4-year graduation rates.

\section{Correlation of AES Scores with Enrollment in STEM Courses}

We calculated the number of science, technology, and mathematics courses each Carleton College participant took, as a fraction of the total number of courses they enrolled in during their first year of college. Carleton College does not offer engineering courses). Two of the five AES scores correlated at a statistically significant or marginally statistically significant level with this measure: Skills $(\mathbf{r}=.17, \mathbf{p}<.06)$ and Interdisciplinary Understanding $(\mathbf{r}=.19, \mathbf{p}<.05)$.

\section{Correlation of AES Scores with Decision-Making Performance}

Carleton College students were surveyed about seven different decisions they were in the process of making over the interval studied. For each of these decisions, we calculated the "decision map size" consisting of the number of different options the participant reported under active consideration, multiplied by the number of different criteria or factors they reported using to decide among these options. Decision map size indexes the number of pieces of information a person considers when making a decision. We computed the mean decision map size across all seven decisions. All five of the AES scales correlated with this measure as follows: Comfort, $\mathbf{r}=.31, \mathbf{p}$ $<.001$; Skills, $\mathbf{r}=.27, \mathbf{p}<.01$; Liberal Arts, $\mathbf{r}=.26, \mathbf{p}<.01$; Interdisciplinary Understanding, $\mathbf{r}=$ $.30, \mathbf{p}<.001$; Future Planning, $\mathbf{r}=.33, \mathbf{p}<.001$. The Overall AES score also correlated significantly with this measure, $\mathbf{r}=.34, \mathbf{p}<.001$.

Table 4 shows a breakdown of correlations among AES scores and decision map sizes for individual decisions. As can be seen, correlations are stronger for academic decisions made later in the first year (course selection and major) - that is, during the period in which students can reasonably be expected to be thinking actively about making their major decision. 
Galotti, Clare, McManus, and Nixon

Table 4. Correlations of AES Scores (Session 2) with Decision Map Size for Individual Decisions

\begin{tabular}{|l|l|l|l|l|l|l|l|}
\hline AES Score & $\begin{array}{l}\text { Winter } \\
\text { Courses }\end{array}$ & $\begin{array}{l}\text { Spring } \\
\text { Courses }\end{array}$ & $\begin{array}{l}\text { Major } \\
\text { (first year) }\end{array}$ & $\begin{array}{l}\text { Fall } \\
\text { Housing }\end{array}$ & $\begin{array}{l}\text { Summer } \\
\text { Plans }\end{array}$ & $\begin{array}{l}\text { Fall } \\
\text { Courses }\end{array}$ & $\begin{array}{l}\text { Major } \\
\text { (soph year) }\end{array}$ \\
\hline Comfortable & .14 & $.24^{* *}$ & $.18^{*}$ & .11 & $.26^{* *}$ & $.25^{*}$ & -.04 \\
\hline Skills & .06 & $.21^{*}$ & $.28^{* * *}$ & .08 & $.20^{*}$ & $.20^{*}$ & .05 \\
\hline Liberal Arts & .14 & $.21^{*}$ & $.24^{* * *}$ & $.19^{*}$ & .09 & .15 & .06 \\
\hline Interdisciplinary & .15 & $.26^{* *}$ & $.30^{* * *}$ & .10 & .15 & $.21^{*}$ & .04 \\
\hline Future Planning & .07 & $.29^{* * *}$ & $.35^{* * *}$ & .15 & .15 & $.28^{* * *}$ & .14 \\
\hline $\begin{array}{l}\text { Overall AES } \\
\text { Score }\end{array}$ & .13 & $.27^{* * *}$ & $.31^{* * *}$ & .15 & $.20 *$ & $.25^{* *}$ & .07 \\
\hline
\end{tabular}

Correlations of AES Scores with Other Individual Differences Variables

We computed correlations among the five AES scale scores and the other self-reported individual differences measures: Need for Cognition, and Planning, separately for each institution. Table 5 presents these correlations and shows moderately strong correlations throughout. The pattern of correlations shows a slight difference between the two institutions, and the correlations are uniformly stronger in the Colby-Sawyer sample.

Journal of the Scholarship of Teaching and Learning, Vol. 16, No. 5, October 2016.

josotl.indiana.edu 
Galotti, Clare, McManus, and Nixon

Table 5. Correlations Among AES Scale Scores (Session 2) and Other Individual Difference Measures

(A) Carleton College Sample $(\mathrm{N}=142)$

\begin{tabular}{|l|l|l|}
\hline AES Scale Score & $\begin{array}{l}\text { Need for } \\
\text { Cognition }\end{array}$ & $\begin{array}{l}\text { Planning } \\
\text { Score }\end{array}$ \\
\hline Comfortable & $.30^{* * *}$ & $.23^{* *}$ \\
\hline Skills & $.36^{* * *}$ & $.18^{*}$ \\
\hline Liberal Arts & $.40^{* * *}$ & $.27^{* * *}$ \\
\hline Interdisciplinary & $.36^{* * *}$ & $.22^{* *}$ \\
\hline Future Planning & $.28^{* * *}$ & .16 \\
\hline Overall AES & $.37^{* * *}$ & $.22^{* *}$ \\
\hline
\end{tabular}

(B) Colby-Sawyer Sample ( $\mathrm{N}=761)$

\begin{tabular}{|c|c|c|}
\hline AES Scale Score & $\begin{array}{l}\text { Need for } \\
\text { Cognition }\end{array}$ & $\begin{array}{l}\text { Planning } \\
\text { Score }\end{array}$ \\
\hline Comfortable & $.37 * * *$ & $.49 * * *$ \\
\hline Skills & $.55^{* * *}$ & $.46^{* * *}$ \\
\hline Liberal Arts & $.38 * * *$ & $.46 * * *$ \\
\hline Interdisciplinary & $.50 * * *$ & $.51 * * *$ \\
\hline Future Planning & $.37 * * *$ & $.39 * * *$ \\
\hline Overall AES & $.49 * * *$ & $.53 * * *$ \\
\hline
\end{tabular}

Journal of the Scholarship of Teaching and Learning, Vol. 16, No. 5, October 2016. josotl.indiana.edu 


\section{Discussion}

Data from two independent and relatively large samples indicates that we have developed an instrument with reasonable internal reliability and test-retest reliability with scales that predict some relevant behaviors in college students in liberal arts settings. Different scales show different patterns of correlations with behavioral variables and different patterns of stability and change.

The Comfortable in College scale scores, for example, correlated significantly with retention measures, whereas no other AES scale scores did. These scale scores were also particularly stable over time, showing very little change from session to session. This in turn suggests that the initial level of ease students feel on a campus-their perception that they can speak freely, approach instructors, feel included as part of a learning community-remains stable from early on in their academic career. Whether this reflects something more than the common finding that first impressions carry a disproportionate weight in the formation of attitudes remains for future investigation. It might be possible to use these scores to identify students who are at risk of dropping out early on in the first year experience.

The Skills scale scores, in contrast, tended to decline over time. Inspection of Appendix 1 shows that these scores reflect students' sense of their own reading, problem-solving, data interpretation, writing, communication, and other academic skills. These scores showed particularly strong correlations with other self-reported measures of cognitive preference, specifically, Need for Cognition and Planning scores. They also correlated marginally significantly with STEM course enrollment. Why would students perceive their academic skills as declining? We speculate that it may be that experience in college broadens and deepens their view of what strong writing or clear understanding are. Put another way, liberal arts college experience may help students come to grips with the idea that there is a vast amount to learn, and may address some initial overconfidence in their own knowledge and self-assessment.

Liberal Arts Understanding scale scores reflect a student's comprehension of what a liberal arts education is, as distinguished from a pre-professional course of study. They also indicate a student's self-reported ability to see a "big picture” of an institution's curriculum-why different parts of the curriculum are included and how they fit together. Liberal Arts scale scores showed the highest correlation over the longest intervals, but a very different pattern of longitudinal change, that of an inverted-U. We wonder again if this reflects a maturation of students' understanding and a lessening of their initial overconfidence in their own appreciation of what a liberal arts education entails.

The Interdisciplinary Understanding scale scores reflect students' self-reported ability to draw connections across individual courses, and to understand that different questions can be meaningfully approached from multiple vantage points. These scores correlated significantly with STEM enrollments, which in turn might suggest ways of encouraging students to take more STEM courses: Having instructors make explicit note of interdisciplinary connections of STEM fields to those in the humanities and social sciences.

Interdisciplinary scale scores declined slightly over time, and showed moderate correlations with decision map sizes for important academic decisions faced in the latter part of the students' first year of college, such as choosing a major or choosing courses late in the first year and early in the second. One explanation for these correlations is that toward the end of their first year students are thinking about their major, and those who are thinking about it in the most complex ways - considering the most information-are also likely to seek out connections across courses. Further work is required to explore and test this possibility.

Journal of the Scholarship of Teaching and Learning, Vol. 16, No. 5, October 2016. josotl.indiana.edu 
Lastly, Future Planning scale scores showed some of the least amount of longitudinal stability, but showed a pattern of overall growth over time. One likely explanation of the low stability is that as students progress from their first to their second year, their plans for future courses naturally change, as they complete different requirements, explore different majors, and discover new interests (one of the goals of a liberal arts education). These scores also showed moderately strong correlations with decision map sizes for important academic decisions faced in the latter part of the students' first year of college, likely because as students start considering possible majors, they focus on requirements more intentionally.

In the study, we included possible correlates of two different kinds: self-report and behavioral. We believe that both kinds of measures are important. Self-report measures provide information about how students describe their own attitudes, values, abilities, and proclivities-in short, they reflect internal insights of the participant. Behavioral measures provide less insight, but more publically observable indices of performance in real-life contexts.

Of course, standard cautions apply when evaluating our work. We collected data from students at only two institutions, both of which were residential liberal arts colleges. How well the scales would do at a larger university or other institution is as yet unknown. Further adoption of the AES would help us to address this question.

Insights derived from the AES have the potential to serve as an important complement to existing assessment efforts in cases in which colleges and universities rooted in the liberal arts seek to examine student perceptions of the purposes and goals of a liberal arts education as they progress through their undergraduate careers. We hope that this instrument can be of both theoretical and practical help to faculty and staff working on assessment issues within liberal arts contexts. We believe the AES measures a student's perception and understanding of important dimensions of a liberal arts education, and predicts some important educationally relevant behaviors. Longitudinal and cohort responses to the AES could help institutions to understand how well they accomplish the goals of liberal education in the eyes of the student, as well as measure any changes in how well those goals are met as program or curriculum changes are implemented.

\section{Acknowledgements}

Support was provided through a grant from the Howard Hughes Medical Institute to Carleton College (Grant No. 52006286); as well as faculty endowment grants from the Dean of the College office, Carleton College, to the first author. We thank Hillary Wiener, Jane Tandler, Amy Murdoch, Samantha Drogue, Stephanie Moberg, Christina Veatch, Andrea Rockwood, Kelsey Han, Lauren Hickman, Tasha Rhoads, Kelley Stevens, Johanna Williams, Naomi Fine, Karen McCleary, Jessa Youso, and Todd Coy for assistance with data collection and analysis, and Megan Meads and Timothy Oliver for assistance with manuscript preparation. 


\section{References}

Bloxham, S., and Boyd, P. (2007). Developing effective assessment in higher education. New York, NY: Open University Press.

Cacioppo, J. T., and Petty, R. E. (1982). The need for cognition. Journal of Personality and Social Psychology, 42 (1): 116-131. doi:10.1037/0022-3514.421.116

http://search.ebscohost.com/login.aspx?direct=true\&db=pdh\&AN=1982-22487-001\&site=ehost-

live

Carnegie Foundation for the Advancement of Teaching 2013. http://classifications.carnegiefoundation.org. Center for Postsecondary Research 2016. http://nsse.indiana.edu/pdf/modules/2015/NSSE\%202015\%20Development\%20of\%20Transfera ble\%20Skills\%20Module.pdf

Clinchy, B. (2002). Revisiting "Women’s Ways of Knowing.” In B. K. Hofer and P. R. Pintrich (Eds.), Personal epistemology: The psychology of beliefs about knowledge and knowing (pp. 6387). Mahwah, NJ: Erlbaum.

Colby Sawyer College (2013). Fast facts. Retrieved from http://www.colbysawyer.edu/about/facts.html

Elveton, R. O., Galotti, K. M., Komatsu, L. K., Rand, M. S., and Singer, S. R. 2000. "Origins and Mind: An Integrated Academic Experience for New Students.” Liberal Education, 86 (1): $32-40$.

Galotti, K. M. 1999. “Making a "Major” Real-Life Decision: College Students Choosing an Academic Major.” Journal of Educational Psychology, 91 (2): 379-387. doi:10.1037/00220663.91.2.379

Galotti, K. M. 2007. “Decision Structuring in Important Real-Life Choices.” Psychological Science, 18 (4): 320-325. doi:10.1111/j.1467-9280.2007.01898.x

Galotti, K. M. and Tinkelenberg, C. E. 2009. "Real-Life Decision Making: Parents Choosing a First-Grade Placement.” American Journal of Psychology, 122 (4): 455-468.

Heywood, J. (2000). Assessment in higher education. London, ENG: Jessica Kingsley Publishers.

Hofer, B. K. (2001). Personal epistemology research: Implications for learning and teaching. Journal of Educational Psychology Review, 13 (4): 353-383. doi:10.1023/A:1011965830686 http://link.springer.com/article/10.1023/A:1011965830686

Hurtado, S., Griffin, K. A., Arellano, L., and Cuellar, M. (2008). Assessing the value of climate assessments: Progress and future directions. Journal of Diversity in Higher Education, 1 (4): 204-221. doi:10.1037/a0014009

Journal of the Scholarship of Teaching and Learning, Vol. 16, No. 5, October 2016. josotl.indiana.edu 
http://search.ebscohost.com/login.aspx?direct=true\&db=pdh\&AN=2008-18230-002\&site=ehostlive

King, P. M. and Kitchener, K. S. (2004). Reflective judgment: Theory and research on the development of rpistemic assumptions through adulthood. Educational Psychologist, 39 (1): 518. doi:10.1207/s15326985ep3901_2 http://search.ebscohost.com/login.aspx?direct=true\&db=keh\&AN=12526499\&site=ehost-live

King, P. M. and Kitchener, K. S. Eds. (1994). Developing reflective judgment: Understanding and promoting intellectual growth and critical thinking in adolescents and adults. San Francisco, CA: Jossey-Bass.

Kitchener, K. S., and King, P. M. (1981). Reflective judgment: Concepts of justification and their relationship to age and education. Journal of Applied Developmental Psychology, 2 (2): 89-116. doi:10.1016/0193-3973(81)90032-0

Klein, S., Benjamin, R., Shavelson, R., and Bolus,R. (2007). The collegiate learning assessment: facts and fantasies. Evaluation Review, 31 (5): 415-439. doi:10.1177/0193841X07303318. http://citeseerx.ist.psu.edu/viewdoc/download?doi=10.1.1.134.383\&rep=rep1\&type=pdf

Kuh, G. D. (2001). Assessing what really matters to student learning: Inside the national survey of student engagement. Change: The Magazine of Higher Learning, 33 (3): 10-17.

doi:10.1080/00091380109601795.http://www.tandfonline.com/doi/pdf/10.1080/0009138010960 $\underline{1795}$

Lawrence, J. 2010a. Class of 2013 Profile: Highlights. Retrieved from http://apps.carleton.edu/admissions/apply/requirements/PastProfiles/2013profile/highl ights/

Lawrence, J. 2010b. Diversity. Retrieved from http://apps.carleton.edu/admissions/topics/diversity/

Magolda, M. B., King P. M., Taylor, K. B., and Wakefield, K. M. (2012). Decreasing authority dependence during the first year of college. Journal of College Student Development, 53 (3): 418-435. doi:10.1353/csd.2012.0040 http://muse.jhu.edu/journals/journal_of_college_student_development/v053/53.3.baxter$\underline{\text { magolda.pdf }}$

Nussbaum, M. C. (2010). Not for profit: Why democracy needs the humanities. Princeton, NJ: Princeton University Press.

Palomba, C. A., and Banta, T. W. (1999). Assessment essentials: Planning, implementing, and improving assessment in higher education. San Francisco, CA: Jossey-Bass.

Perry, W. G. (1970). Forms of intellectual and ethical development in the college years: A scheme. New York, NY: Holt, Rinehart, \& Winston. 
Secolsky, C., and Denison, D. B. Eds. (2012). Handbook on measurement, assessment, and evaluation in higher education. New York, NY: Routledge.

Seifert, T. A., Goodman, K., King, P. M., and Magolda, M. B. Baxter. (2010). Using mixed methods to study first-year college impact on liberal arts learning outcomes. Journal of Mixed Methods Research, 4 (3): 248-267. doi:10.1177//15586898103474960. http://www.researchgate.net/profile/Kathleen_Goodman/publication/237074774_Using_mixed methods_to_study_firstyear_college_impact_on_liberal_arts_learning_outcomes/links/02e7e51b41c8e075c6000000.pdf

Suskie, L. (2009). Assessing student learning: A common sense guide ( $2^{\text {nd }}$ ed.). San Francisco, CA: Jossey-Bass.http://sa.utep.edu/wp-content/blogs.dir/64/files/2013/10/What-is-GoodAssessment-Suskie-3.pdf

Simons, D. J. and Galotti, K. M. 1992. "Everyday Planning: An Analysis of Time Management.” Bulletin of the Psychonomic Society, 30 (1): 61-64.U. S. Department of Education. (2006). A test of leadership: Charting the future of American higher education. (Report of the commission appointed by Secretary of Education Margaret Spellings). Washington, DC: Author. 


\section{Appendix 1. Academic Experience Scale (AES) Items by Scale}

Bold indicates negatively worded item (score must be reverse-coded)

Interdisciplinary Understanding

1. I understand connections among different disciplines, such as the humanities, sciences, and social sciences.

2. My classes this term complement each other.

3. My coursework shows me how different disciplines intersect and relate to one another.

4. I find out-of-class opportunities to have in-depth and integrative discussions with other students about issues that come up in my classes.

5. I understand how people in different disciplines approach the same question in different ways.

6. I understand how people can translate one concept or idea from one discipline to another.

7. I feel confident in my ability to integrate different disciplinary perspectives to produce a new understanding of idea.

8. I frequently take what I've learned in one class and apply it to another.

9. I feel confident in my ability to see differences among disciplinary perspectives in understanding an issue or a problem.

Liberal Arts Understanding

1. My classes this term offer me a reasonable and broad view of intellectual inquiry.

2. I understand the rationale for distribution requirements at [college] (whether or not I agree with it).

3. I understand why science and mathematics courses are considered "liberal arts".

4. I understand why social science courses are considered "liberal arts".

5. I understand why humanities courses are considered "liberal arts".

6. I understand why literature courses are considered "liberal arts".

7. I understand why arts and music courses are considered "liberal arts".

8. I am comfortable with ambiguity in approaching a problem or question.

9. I understand that the purpose of my education at [college] is not necessarily to learn facts but to train myself to think in new ways.

Skills

1. I have strong writing skills.

2. I have strong critical thinking skills.

3. I have strong reading skills.

4. I have strong skills in solving intellectual problems.

5. I have strong skills in interpreting data.

6. I have strong skills in oral communication.

7. I have strong skills in working with models of complex systems.

8. I am able to grasp important theoretical ideas in my classes.

9. When I am challenged by a task, I work at it until I master it.

Journal of the Scholarship of Teaching and Learning, Vol. 16, No. 5, October 2016. josotl.indiana.edu 
Comfortable at College

1. My classes this term, as a whole, are challenging.

2. I feel I am a part of a learning community with other students in my classes.

3. I would recommend the classes I'm taking right now to a friend with similar interests to mine.

4. My high school background has prepared me well for college.

5. I am able to express my thoughts and ideas freely in conversations with people in my dorm and in my classes.

6. I can approach my professors this term with concerns and thoughts both in and out of the classroom.

7. I am pleased with the progress I am making in my classes.

8. I enjoy being challenged to think in new ways and consider alternative perspectives.

9. I feel comfortable/ at ease most of the time when I am at [college].

Future (Academic) Plans

1. I would consider taking interdisciplinary courses in the future.

2. I would consider an interdisciplinary program (concentration or off-campus study program) in the future.

3. I would consider an interdisciplinary major or special major in the future.

4. My classes this term have helped me think about which major to select.

5. In the future I plan to take classes that build on what I'm learning in my current classes.

6. I am taking classes to help determine what subject I am most interested in before determining my major.

7. I plan to explore potential majors and concentrations while fulfilling my distribution requirements.

8. I plan on taking easy classes to boost my GPA while fulfilling my distribution requirements.

9. In the future, I will likely still be thinking about the ideas I've been discussing in my current classes. 